\title{
Study on Corrosion Resistance of New Type of Magnesium Phosphate Cement
}

\author{
Jun Liü,2,a , Jinsong Ma ${ }^{1, b}$,Chang Liü,c \\ ${ }^{1}$ School of Materials Science and Engineering, Shenyang Jianzhu University, Shenyang, China \\ ${ }^{2}$ School of Materials Science and Engineering, Shenyang Ligong University, Shenyang, China \\ aEmail:liujun2699@126.com, ${ }^{\text {b} E m a i l: 383973511 @ q q . c o m, ~}{ }^{c}$ Email:943615701@qq.com
}

Keywords: Magnesium phosphate cement; silicate - magnesium phosphate cement; strength; acid and alkali salt corrosion

Abstract. Magnesium phosphate cement blended with Portland cement were cured in $\mathrm{MgCl} 2$, $\mathrm{Na} 2 \mathrm{SO} 4, \mathrm{NaCl}, \mathrm{HCl}$ and $\mathrm{NaOH}$ solutions, and the compressive, flexural strength and microstructure were approached and their corrosion resistance were studied. The results show that the corrosion resistance of magnesium phosphate cement (MPC) is good, but poor in the $\mathrm{HCl}$ solution and the worst in $\mathrm{NaOH}$ solution. In $\mathrm{HCl}$ and $\mathrm{NaOH}$ environment, the corrosion retention of the Portland cement modified phosphate cement mortar (PCMPC) was $80.2 \%, 74.8 \%$, and $73.4 \%$ and $71.6 \%$ for the MPC respectively. In general, the corrosion resistance of the PCMPC was better than that of the MPC. SEM results show that the chemical solution environment will destroy the flocculation gel structure formed by the hydration of magnesium phosphate cement, leading to porous structure and lower density and thus deterioration of the corrosion resistance of magnesium phosphate cement mortar.

\section{Introduction}

Magnesium phosphate cement (MPC) is usually composed of magnesium oxide, phosphate and retarder adding with a certain ratio of water, forming a high degree of crystallization of the material [1]. MPC, as a new type of cement material, has the advantages of short setting time, high early strength, potential to application at negative temperature, good adhesion, good wear resistance and good frost resistance, but it is proved that the corrosion resistance of magnesium phosphate cement can not meet the construction requirements [2].

Recently, some scholars at home and abroad have begun to study the effect of mineral admixtures on the performance of MPC cement. Fly ash can not only play active effect, micro-aggregate effect and morphological effect, but also adsorption effect on MPC [3]; proper amount of fly ash not only reduces the cost of MPC, but also improves the stability of the specimens cured in acid and alkali salt solution [4]. Portland cement can improve the late strength of magnesium phosphate cement [5]. However, it is necessary to study the effect of different admixtures on the corrosion resistance of MPC and its mechanism; Studying the influence of different admixtures on the corrosion resistance of MPC is also necessary.

In this paper, the effects of fly ash and common Portland cement on the corrosion resistance of MPC were studied. The mechanism of corrosion resistance of acid and alkali salt was analyzed from the microstructure, and putting forward the method to improve the corrosion resistance of MPC, which provides the theoretical basis for the engineering application of Magnesium Phosphate Cement.

\section{Experimental}

Test raw materials. The re-burned $\mathrm{MgO}(\mathrm{M})$ is pure industrial grade, produced by Haicheng Qianyuan Refractories Co., Ltd. in Liaoning Province. The specific chemical composition is shown in Table 1; Potassium dihydrogen phosphate $\left(\mathrm{KH}_{2} \mathrm{PO}_{4}\right.$, abbreviated as $\left.\mathrm{P}\right)$ is an industrial pure grade, produced by Tianjin Binhai welfare chemical plant, with net content of $98.56 \%$; In this paper, retarder is borax, chemical formula: $\mathrm{Na}_{2} \mathrm{~B}_{4} \mathrm{O}_{7} \cdot 10 \mathrm{H}_{2} \mathrm{O}$, chemical pure, abbreviated as $\mathrm{B}$, the content of not less than 99.5\%; Portland cement, used in this article is 42.5 Portland cement, 42.5 Portland cement not only has 
good performance, low price, and widely distributing, and is with hardening and rapid condensation, high strength, good resistance to freeze-thaw cycle, good durability and so on. The cement used in this test was 42.5 Portland cement produced by Dalian Odoca Cement Co., Ltd. The main chemical composition of the cement is shown in Table 2; Fly ash, the main chemical composition of the used fly ash is shown in Table 3.

Table 1 Magnesium oxide chemical composition $/ \%$

\begin{tabular}{cccccc}
\hline Oxide & $\mathrm{MgO}$ & $\mathrm{SiO}_{2}$ & $\mathrm{CaO}$ & $\mathrm{Al}_{2} \mathrm{O}_{3}$ & $\mathrm{Fe}_{2} \mathrm{O}_{3}$ \\
\hline content/\% & 92 & 0.7 & 1.36 & 0.3 & 0.3 \\
\hline
\end{tabular}

Table 2 Chemical composition of cement $/ \%$

\begin{tabular}{cccccccc}
\hline $\mathrm{SiO}_{2}$ & $\mathrm{Al}_{2} \mathrm{O}_{3}$ & $\mathrm{Fe}_{2} \mathrm{O}_{3}$ & $\mathrm{CaO}$ & $\mathrm{MgO}$ & $\mathrm{SO}_{3}$ & $\mathrm{R}_{2} \mathrm{O}$ & $\begin{array}{c}\text { Loss of } \\
\text { ignition }\end{array}$ \\
\hline 21.72 & 5.81 & 4.33 & 62.41 & 1.73 & 2.56 & 0.50 & 1.47 \\
\hline
\end{tabular}

Table 3 Chemical composition of fly ash $/ \%$

\begin{tabular}{cccccccc}
\hline $\mathrm{SiO}_{2}$ & $\mathrm{Al}_{2} \mathrm{O}_{3}$ & $\mathrm{CaO}$ & $\mathrm{MgO}$ & $\mathrm{Fe}_{2} \mathrm{O}_{3}$ & $\mathrm{~K}_{2} \mathrm{O}$ & $\mathrm{Na}_{2} \mathrm{O}$ & $\mathrm{SO}_{3}$ \\
\hline 59.95 & 26.78 & 4.35 & 2.30 & 1.53 & 1.25 & 2.75 & 1.46 \\
\hline
\end{tabular}

\section{Preparation and testing of samples}

Preparation of the sample.Refer to the preliminary basic test, the optimal mix ratio was chosen to the experiment. MPC mortar: magnesium phosphate ratio of 4: 1, borax content of $16 \%$, fly ash content of $60 \%$, mortar water and solid ratio of 0.18 , cement-sand ratio 1: 1; PCMPC mortar: The ratio of magnesium to phosphorus is $4: 1$, the content of borax is $16 \%$, the content of fly ash is $60 \%$, the ratio of cement to water is 0.22 , the ratio of cement to sand is $1: 1$, the content of Portland cement is $30 \%$.

Determination of corrosion resistance.Magnesium phosphate cement with size of $40 \mathrm{~mm} \times 40$ $\mathrm{mm} \times 160 \mathrm{~mm}$ was demolded and then maintained at room temperature for 7 days, at a temperature of $(20 \pm 2)^{\circ} \mathrm{C}$ and a relative humidity of $70 \%$. After the initial weight was measured, the specified solution was bubbled into the designated solution period. And then with reference to GB / T17671-1999 "cement mortar strength test method" strength testing was conducted.

Evaluation indicators.In this experiment, the strength loss was used to evaluate the corrosion resistance of magnesium phosphate cement. And the strength retention rate $\mathrm{K}$ (accurate to 0.01) is proposed as the index of corrosion resistance of MPC specimen according to the strength loss. The strength retention rate $\mathrm{K}$ is defined as follows:

$$
K_{\mathrm{t}}=\frac{f}{F} \times 100 \%
$$

$\mathrm{K}_{\mathrm{t}}$ - MPC specimen $\mathrm{t}$ days of strength retention rate;

f- The unconfined compressive strength of MPC specimen, MPa;

F-Unconfined compressive strength of natural maintenance of MPC specimen, MPa.

SEM scanning electron microscopy analysis.Using the S-3400N scanning electron microscope produced by HITACHI Company in Germany, in the natural conservation of 7 days conditions, the internal microstructure of the magnesium phosphate cement sample immersed in 28 days under natural condition was analyzed by SEM scanning electron microscopy. 


\section{Results and analysis}

\section{Effect of compressive strength}

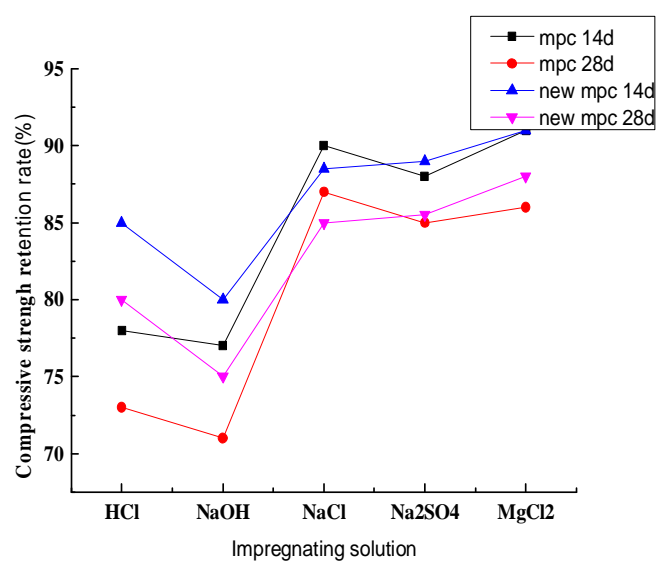

Figure 3.1 MPC mortar and composite MPC mortar in acid and alkali salt solution after immersion strength retention rate

Strength of the MPC mortar and PCMPC in acid and alkali salt solution were presented in Figure 3.1, we can see from the figure, different solution environment, magnesium phosphate cement mortar strength retention rate is different. MPC mortar and MPC composite Portland cement in acid and alkali salt solution after immersion pressure strength retention rate changes in Figure 3.1. We can see from figure 3.1 that, under different solution environment, magnesium phosphate cement mortar strength retention rate is different. The retention rates of compressive strength of the two kinds of cement mortars in $\mathrm{HCl}, \mathrm{NaOH}, \mathrm{NaCl}$ and $\mathrm{Na}_{2} \mathrm{SO}_{4}$ solutions are relatively low, especially in $\mathrm{HCl}$ and $\mathrm{NaOH}$ environments, which is only $73.4 \%, 71.6 \%$ and $80.2 \%, 74.8 \%$. In the $\mathrm{MgCl} 2$ solution, the compressive strength retention of the two mortars is higher than that in the above four solutions.

The reason for the above situation may be that the main hydration product of the MPC cement slurry is eroded, resulting in the loose structure of the cement slurry, which affects the durability of the magnesium phosphate cement. The amount of $\mathrm{k}$-struvite produced is related to the $\mathrm{pH}$ of the solution, and only when the $\mathrm{pH}$ of the solution is moderate, the $\mathrm{pH}$ is usually 8.5. After the conservation of 7 days, most of the MPC cement hydration has been completed.

So the environment of $\mathrm{HCl}$ and $\mathrm{NaOH}$ destroyed a small amount of non-hydrated raw materials to produce the optimal $\mathrm{pH}$ value of struvite, resulting in reducing production of $\mathrm{k}$-struvite, the vast majority of the already generated struvite due to strong acid and alkali dissolution, resulting in loosing MPC structure and lower strength. In $\mathrm{NaCl}, \mathrm{Na}_{2} \mathrm{SO}_{4}$ and $\mathrm{MgCl}_{2}$ solution, the strength loss is less than that in $\mathrm{HCl}$ and $\mathrm{NaOH}$ solution, and the $\mathrm{pH}$ environment of guanaceans is generally between 7.5 and 9.5. Since the $\mathrm{pH}$ value of these three solutions is in this range. There is little effect on the precipitation of struvite, and the structure is denser than that of $\mathrm{HCl}$ and $\mathrm{NaOH}$ solution.

\section{Effect of flexural strength}

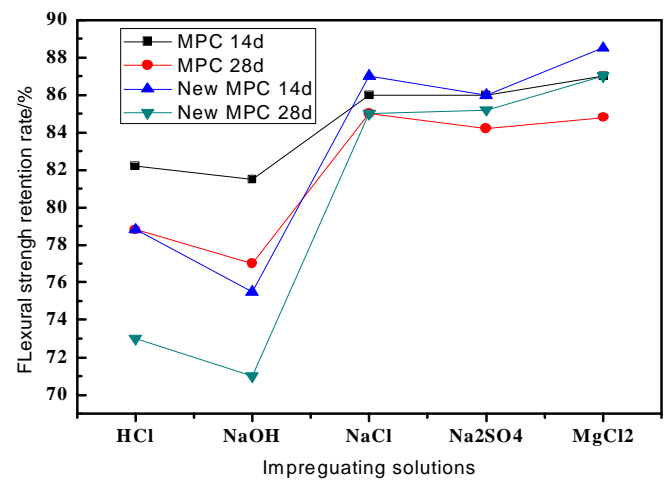

Figure 3.2 MPC mortar and MPC composite mortar in acid and alkali salt solution after immersion strength retention rate changes 
Strength retention rate of the MPC mortar and PCMPC in acid and alkali salt solution are shown in Figure 3.2. From the data structure, the flexural strength retention rate of the two magnesium phosphate cement mortars is generally lower than its compressive strength retention rate. From Figure 3.2 we can see that under different solution environment, flexural strength retention of MPC $(14 \mathrm{~d}$ and 28d) is different, this is consistent with the data characteristics of MPC mortar compressive strength retention rate, the retention rate of the two cement mortars at $14 \mathrm{~d}$ and $28 \mathrm{~d}$ in the $\mathrm{HCl}, \mathrm{NaOH}, \mathrm{NaCl}$ and $\mathrm{Na}_{2} \mathrm{SO}_{4}$ environments are relatively low. In the $\mathrm{HCl}, \mathrm{NaOH}$ environment, the retention retention rates of the two magnesium phosphate cement mortars were only $78.6 \%, 76.8 \%$ and $73.2 \%$ and $71.3 \%$, respectively. And the mortar in the $\mathrm{MgCl}_{2}$ solution has higher flexural strength retention than the other four solutions. In the same way, we also found that MPC mortar and PCMPC mortar, in different solution environment for comparison, MPC composite Portland cement mortar strength retention rate is slightly better than MPC mortar strength retention rate. Especially in the tap water and strong acid, alkali solution, MPC composite mortar is better than MPC mortar. The reason for this phenomenon may be due to the hydration product of Portland cement in composite magnesium phosphate cement mortar and the hydration product of magnesium phosphate cement, which is further caused by the internal structure of slurry.

\section{Microstructure analysis}

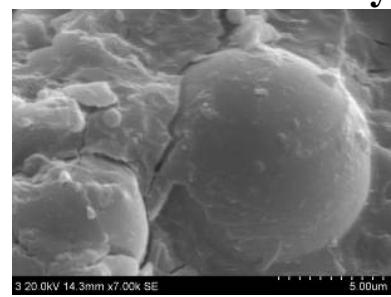

(a) $\mathrm{Na}_{2} \mathrm{SO}_{4}$

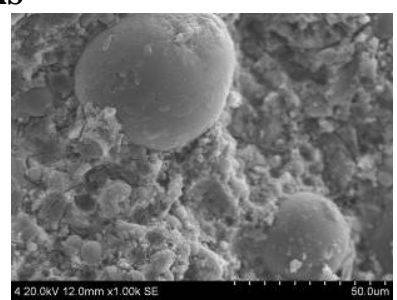

(b) $\mathrm{MgCl}_{2}$

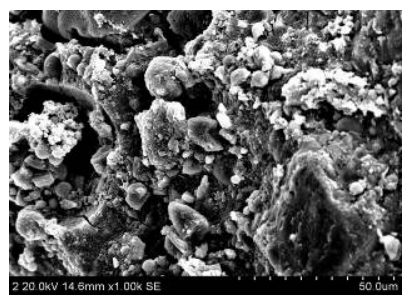

(c) $\mathrm{NaOH}$

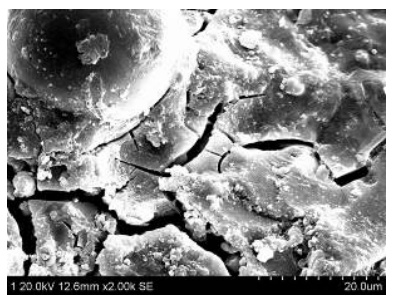

(d) $\mathrm{HCl}$

Figure 3.3 Hydrated microscopic image of magnesium phosphate cement mortar in five chemical solutions soaked for 28 days

As can be seen from Figure 3.3, magnesium phosphate cement mortar in $\mathrm{Na}_{2} \mathrm{SO}_{4}$ solution environment, the erosion of $\mathrm{SO}_{4}{ }^{2-}$ is smaller, but under the action of water, a small part of the hydration of the formation of flocculent gel. $\mathrm{MgCl}_{2}$ solution on the magnesium phosphate cement mortar less erosion, due to the existence of free $\mathrm{Mg}^{2+}$ ions in the environment, inhibited the hydration gel structure of the dissolved, the overall structure of dense. Magnesium phosphate cement mortar is severely eroded in $\mathrm{HCl}$ solution, and most of the hydrated guanillocene gel is destroyed by acid, so that the whole magnesium phosphate cement system has a loose porous structure, while the unhydrated $\mathrm{MgO}$ particles are exposed to erosion in the environment, preventing the further hydration. Magnesium phosphate cement mortar is most eroded in $\mathrm{NaOH}$ solution. Under strong alkaline environment, the solution not only destroys the flocculated gel formed by hydration, but also directly destroys the exposed fly ash particles.

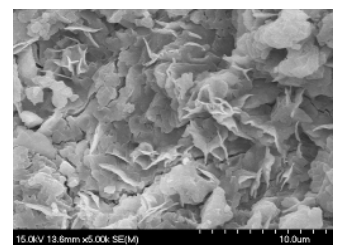

(a) $\mathrm{HCl}$

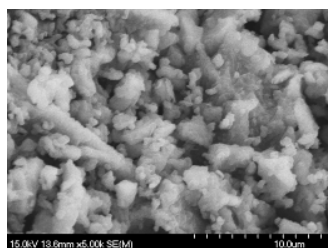

(b) $\mathrm{NaOH}$

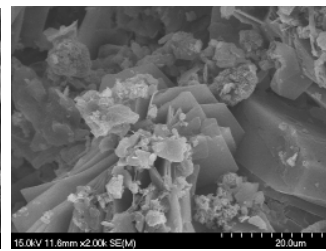

(c) $\mathrm{Na}_{2} \mathrm{SO}_{4}$

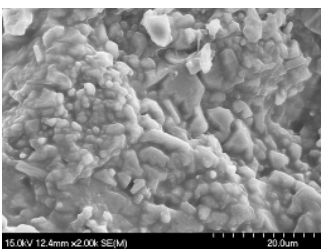

(d) $\mathrm{MgCl}_{2}$

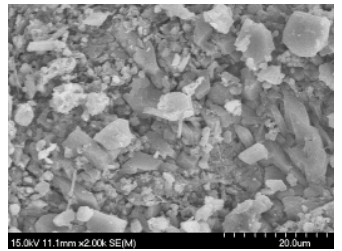

(e) $\mathrm{NaCl}$

Figure 3.4 composite magnesium phosphate cement mortar in five chemical solution soaking $28 \mathrm{~d}$ hydration microscopic image

It can be seen from Figure 3.4, after soaking in $\mathrm{HCl}$ and $\mathrm{NaOH}$ solution, the slurry inside of the the PCMPC mortar owned many cracks, but better than MPC mortar in $\mathrm{HCl}$ and $\mathrm{NaOH}$ solution soaking. Indicating that the composite magnesium phosphate mortar resistance to strong acid and alkali is better than pure magnesium phosphate cement, after adding silicate cement hydrate calcium silicate and calcium hydroxide effectively control the $\mathrm{pH}$ value of magnesium phosphate cement hydration environment, it is conducive to the formation of MKP, but also to prevent the strong acid and alkali of 
magnesium phosphate hydration products dissolved, effectively improving the chemical resistance of cement mortar. PCMPC mortar in $\mathrm{Na}_{2} \mathrm{SO}_{4}, \mathrm{MgCl}_{2}$ and $\mathrm{NaCl}$ solution got less number of pores. The pores of the cement slurry are less than the cement slurry in the $\mathrm{HCl}$ and $\mathrm{NaOH}$ solutions, which are more resistant to chemical and less aggressive to $\mathrm{SO}_{4}{ }^{2-}$. PCMPC mortar structure is more compact, resistant to $\mathrm{MgCl}_{2}$ and $\mathrm{NaCl}$ solution corrosion is better.

\section{Conclusions}

MPC mortar and PCMPC cement mortar were cured in the five chemical solutions compression and bending strength retention rate were different. Two of the cement mortar in $\mathrm{HCl}$ and $\mathrm{NaOH}$ solution strength retention rate is only $80 \%$ and $70 \%$. The strength retention rate of the two kinds of cement mortar in $\mathrm{Na}_{2} \mathrm{SO}_{4}$ and $\mathrm{NaCl}$ solution are relatively good, and the retention rate of the two kinds of cement mortar in $\mathrm{MgCl}_{2}$ solution is about $90 \%$, which indicates that the corrosion resistance of MPC is better. In general, the corrosion resistance of PCMPC mortar is better than that of MPC mortar.

Chemical solution reduces the strength of MPC mortar, which mainly destructs magnesium phosphate cement hydrated formation of struvite flocculent gel structure, reduce the density, resulting in decreased MPC strength. Hydrated calcium silicate formed in PCMPC prevents the chemical solution of MKP dissolution, while regulating the $\mathrm{pH}$ of MPC hydration environment, and promoting the formation of hydrated product MKP, Hydrated calcium silicate and other silicate cement hydration products and MKP magnesium phosphate cement hydration products interlock together, so that the PCMPC mortar is with densestructure and good corrosion resistance.

\section{Acknowledgments}

This work was financially supported by Shenyang Science and Technology Project 17-48-2-00.

\section{References}

[1] Ruan Wenjun, Jing Xiangdang, Wang Biao. Optimization of Phosphate Retarder and Properties of Cement Composite Slurry[J]. Geology and Exploration, 2002, 38(4):83-86.

[2] Li Dongxu, Li Pengxiao, Feng Chunhua. Study on Water Resistance of Magnesium Phosphate Cement[J]. Journal of Building Materials, 2009, 12(5):505-510.

[3] Lin Wei, Sun Wei, Li Zongjing. Study on Fly Ash Effect in Magnesium Phosphate Cement [J]. Journal of Building Materials, 2010, 13 (6): 716-721.

[4] Chen Bing, Wu Zhen, Wu Xueping. Experimental Study on Modification of Magnesium Phosphate Cement [J]. Journal of Wuhan University of Technology www.ilib.cn, 2011 (4): 29-34.

[5] Ding Tao, Li Zongjin. Preparation and Properties of Early Strength Phosphosilicate Cement [J]. Chinese Journal of Materials Research, 2006, 20 (2): 141-147. 